\title{
Technology for offshore wind turbines
}

\author{
G. Moe ${ }^{1}$, J. M. Niedzwecki ${ }^{2}$, H. Long ${ }^{1}$, R. Lubbad ${ }^{1}$ \& S.-P. Breton ${ }^{1}$ \\ ${ }^{I}$ Norwegian Institute of Science and Technology, Trondheim, Norway \\ ${ }^{2}$ Texas A\&M University, USA
}

\begin{abstract}
A selective and incomplete review of the status of the development of offshore wind turbines is given. The main focus is on state of the art and emerging solutions, and emphasis is on solutions for deep water.

Keywords: offshore wind turbines, deep water, floating wind turbines, truss towers.
\end{abstract}

\section{Introduction}

\subsection{General}

The world consumption of oil and gas is increasing by about $2 \%$ each year, in recent years mainly due to economic growth in Asia, while new hydrocarbon resources are not found in sufficient quantities to keep up with this apparent ever-increasing demand. Some experts argue that we are at or close to 'peak oil', i.e. that the all-time maximum production rate has been reached. If that is correct oil prices will have to rise until oil consumption matches the slowly decreasing oil availability. The necessary strategy to cope with this new situation should probably combine energy conservation with increased energy production from non-petroleum sources. Among the alternative sources are oil tar sands, coal, and nuclear energy, but the two former would cause severe environmental problems, while the latter among other factors has security implications. Wind energy is probably a better alternative, since in good locations energy from wind turbines can be produced at prices that are competitive in today's energy market, even before factoring in their environmental benefits. The problem is that in order to contribute significantly to the energy balance extensive wind park developments are required and then public acceptance becomes uncertain. Therefore offshore 
wind turbines built out of sight from land offer a very attractive alternative, provided the costs are not too high.

As of now the price for energy from offshore turbines is roughly the double of the price from landbased turbines. However, the developers have up to now just moved the landbased solutions offshore, even though the conditions differ considerably. Road transportation imposes severe limitations on the size of landbased turbines, while no such limits exist under offshore conditions. Foundation solutions will be different on land and offshore, and installation may also be done in radically different and possibly less expensive ways. Access for maintenance and repair will be more costly in an ocean environment, but the penalty per kWh will be less the larger each turbine is. Offshore hookup to the electrical net is more costly (per turbine), while visual appearance is nearly irrelevant, if the site is far enough from shore. Accordingly optimal solutions are expected to be different from today's solutions, and the optimal turbine size would for example probably be larger.

\subsection{Some trends in landbased turbine developments}

Landbased wind turbine towers usually have conical steel towers, so-called tubular towers. This shape is chosen mostly for reason of aesthetics, and is not expected to give minimal tower costs. For moderately large wind turbines the cost penalty for the use of this type of tower is moderate, since the manufacturers over time have developed very efficient production apparatuses for them. However, there is a clear trend toward other solutions for the largest turbines. Thus Enercon uses prefab concrete for their E-82, which may have a hub height of up to $108 \mathrm{~m}$, and in-situ cast concrete for their largest turbine, the 4.5 MW E-112, which has a hub height of $124 \mathrm{~m}$. The company SeeBA claims the tallest wind turbine tower in the world with their lattice tower of $160 \mathrm{~m}$ hub height. This particular tower is erected on a site which has moderately strong wind, so the rated power is a modest $2.5 \mathrm{MW}$. The REpower $5 \mathrm{M}$ is at present among the turbine models with the highest rated power, namely $5 \mathrm{MW}$. REpower offers the following tower solutions: (a) steel tubular, (b) concrete and (c) concrete/steel hybrid towers. The hub heights are 100-120 m for onshore sites, and $90 \mathrm{~m}$ for offshore sites. The Multibrid M5000, which has a rated power of $5 \mathrm{MW}$, will be further described under offshore turbines.

Rotors on landbased wind turbines are most often of a three-bladed upwind configuration in which the blades are of glass fibre reinforced plastics. However, there has also been interest in use of the stronger and stiffer carbon fibres for parts of the blades. A three-stage gearbox is used in $80-85 \%$ of modern wind turbines, while so-called direct drive is used for the remainder. Enercon uses electromagnets while Scanwind has chosen to use permanent magnets. The durability of the gear boxes is often considered to be problematic, while the direct drive solutions implemented so far are quite heavy. This is due to the large diameter required on a slowly rotating rotor to accommodate the large number of coils required to generate sufficiently high frequency alternating current. (Hybrid solutions are also possible, as will be seen later in conjunction with Multibrid M5000). Offshore and onshore wind turbines can use the same solutions for the 
rotor and the unit on top of the tower ('nacelle'), but as mentioned earlier, different conditions e.g. as regards accessibility may lead to different choices for the two cases.

The foundations in soft soil are usually made by excavating a large volume, and then filling it with reinforced concrete. On solid rock sites e.g. in Norway, solutions with anchors in holes drilled directly in the rocky subsurface are preferred.

\subsection{What is the optimum size for wind turbines?}

There is a penalty by increasing the size of a wind turbine. Simply put, one is harvesting energy from an area, while building a volume, and if one assumes that all dimensions increase in the same proportion ('geometric similarity') then the volumes increase as length scale cubed, while the areas increase as length scale squared. The assumption that all dimensions should increase in the same proportion is correct as long as the wind loading on the rotor is the dominating force, but when the dominant loading is self weight the growth of weight as a function of length scale will be even faster, see e.g. Moe [4]. A mitigating effect is that the mean wind velocity increases with height, so that a taller wind turbine will experience stronger wind. The simplest model for wind profiles, which unfortunately is rather inaccurate, says that the mean wind velocity increases as height to the power $1 / 7=0.14$, so that the increase of power production with length scale $s$ will be

$$
s^{2}\left(s^{0.14}\right)^{3}=s^{2.42}
$$

The wind profiles at the location of the rotor of large wind turbines will usually be considerably steeper than this, however. Thus data collected by Garrad Hassan, and published by EWEA (2004) indicate that the average increase of power production as a function of length scale is proportional to $\boldsymbol{s}^{\mathbf{2 . 2 3}}$ for the larger wind turbines. This means that the weight per $\mathrm{kWh}$ depends on the length scale as

$$
s^{3} / s^{2.23}=s^{0.77}
$$

i.e. this ratio increases as length scale to the power 0.77 . For example by doubling the turbine height the weight per $\mathrm{kWh}$ will increase by a factor of $2^{2.23}=1.70$. Or, more realistically, if the length scale is increased by $20 \%$ then the turbine weight per $\mathrm{kWh}$ will increase by $15 \%$. If focus is shifted to a wind park, instead of just considering a single wind turbine, then the power production per unit area is to the first approximation the same: the distances in both directions in the horizontal plane must increase in proportion to the length scale. For the Horns Rev wind park a distance of 7 rotor diameters in both directions has been used, see Soerensen et al. [8]. That resulted in power production of about $88 \%$ of what would be the case if there were no wake effects, i.e. if there were no reduction of the incoming flow due to upstream turbines. Again, for a given park area, large wind turbines will produce more, since the rotor will be at a higher altitude, and according to the above this will amount to $s^{0.23}$, i.e. by a doubling of the height the power production will increase by about $17 \%$. 
Or more realistically, a 20\% larger length scale yields about $4.3 \%$ more power for a given park area. Thus for a $20 \%$ larger length scale the power production increases by $50 \%$, while the turbine weight increases by $73 \%$. In addition, the fact that there are fewer turbines for a given park size will diminish the loss due to park wake effects, but probably only by a small amount, unless the number of turbines in each row in the wind direction becomes small.

Another negative effect of increasing size is that the angular velocity of the rotor decreases. To a first approximation the velocity at the tip of the blades will be the same for all rotors, while the length of the periphery of the rotor disc of course increases linearly with length scale. Thus the angular velocity of the rotor and (low-velocity) shaft will be proportional to the inverse of the length scale, so that the necessary gearing ratio will increase linearly with turbine length scale.

\section{Offshore wind turbines}

\subsection{The size of offshore turbines and offshore parks}

Compared to landbased turbines, larger units will be optimal under offshore conditions, to minimize impacts from the increased costs for maintenance and cabling, as indicated earlier. Similarly large wind parks are advantageous because then the costs of DC transformers (if any) and the cabling to connect to the electrical grid can be carried by a larger production. Further, large parks permit more efficient maintenance schemes.

Wind parks may be combined with subsea cables. In fact many subsea cables are planned between countries on the North Sea rim, see van der Tempel et al. (2002), in which also the possibility of combining these with offshore wind parks is discussed. E.g. the NorNed cable between Norway and the Netherlands has a capacity of $700 \mathrm{MW}$. A park hooked up to a cable of this size could transport $700 \mathrm{MW}$ to both sides, while under no-wind conditions the cable would transport power in either direction, according to need. If this park used 280 turbines of $5 \mathrm{MW}$ with a $120 \mathrm{~m}$ rotor diameter, then the distance between the turbines would be $840 \mathrm{~m}$ ( 7 diameters, see above) and the park would cover roughly $280 * 0.84^{2}=200 \mathrm{~km}^{2}$. Considering losses due to park wake effects the number of turbines should be increased to $280 / 0.88=318$, covering an area of $200 / 0.88=227 \mathrm{~km}^{2}$, e.g. a square with sides of about $15 \mathrm{~km}$. Plotted on a map over the North Sea this area is quite modest. For example, the distance from Stavanger to the Ekofisk field is $280 \mathrm{~km}$. Yet the expected yearly electricity production from this park would be about $4 \mathrm{TWh}$, if the wind climate corresponds to 3000 hours of production at rated power. This amounts to roughly $3.5 \%$ of the electricity consumption in Norway, or alternatively to $4 \%$ of the electricity consumption in the Netherlands. For comparison, it can be mentioned that a planned gas power plant on Mongstad, which for years has been a major political issue in Norway, will deliver $280 \mathrm{MW}$, which amounts to $2.45 \mathrm{TWh}$, if run on full production for one year (in addition, the Mongstad plant will produce $350 \mathrm{MW}$ thermal energy). Unfortunately, it is very expensive to connect a wind park to an existing sea cable, and it is now too late to connect a wind park to the NorNed cable. 
Offshore wind turbines may be of two kinds, namely based on either floaters or bottom-fixed units, and the conditions vary considerably between the two.

\subsection{Foundations for bottom-fixed offshore turbines}

The foundations for bottom-fixed offshore turbines depend on turbine size, water depth and soil conditions, to mention what probably are the most important parameters. In Schaumann et al. [5], as part of a paper on wind turbine structures, is given a list and a short discussion of foundation alternatives. That paper is published in German in a well known structures journal. For those who cannot read German a short résumé of the same can be found in Schaumann et al (2004b). Both these papers and several others can be downloaded directly from the internet site www.gigawind.de. In Byrne and Houlsby (2006) a similar list is given, but the item 'suction bucket' is now split in two, namely a 'suction caisson' which represents a single foundation for the entire wind turbine, i.e. an alternative to monopile or gravity foundations, and 'suction piles' which are buckets installed to support the legs of tripods or jackets (the term 'suction pile' is not used by Byrne and Houlsby). A slightly modified combination of the two lists of foundation solutions is as follows:

- Monopile

- Gravity foundation

- Suction caisson

- Piles

- $\quad$ Suction piles

- $\quad$ Tension piles

The monopile foundation has a slightly smaller diameter than the tubular tower that it supports, and is therefore quite wide and can be difficult to drive or drill to a satisfactory depth. After installation the monopile foundation will usually not be perfectly vertical, but using a pile-sleeve connection with a sufficiently large annulus, the monotower can be adjusted to a vertical position and then fixed there by grouting in the annulus. The strength of grouting connections has been studied extensively and is claimed to be satisfactory for such applications.

The gravity foundations at the shallow water Middelgrunden wind park consist of a $17 \mathrm{~m}$ wide concrete base kept in place by gravitation forces and protected from scour by extensive rock fill around the periphery. The base and the lower part of the structure is in one concrete piece, reinforced with tension cables, and have the form of a candlestick into which the turbine tower is mounted by grouting. Gravity foundations for large volume offshore oil structures are equipped with a skirt that may penetrate rather deep into the seafloor, and penetration is often assisted by underpressure. During installation this solution may thus be considered as a 'suction caisson', in the terminology introduced herein. In a patented solution for wind turbine offshore foundations water jets of carefully controlled strength at the pile rim are used to facilitate soil penetration in hard sediments. Suction caissons are suction buckets representing a single cylindrical volume to which underpressure is applied. That means that the moment from the thrust force must be carried by shear stresses along the 
cylinder walls, assisted by penetration resistance on the downwind side of the cylinder.

Piles or suction piles can be used in the same way as for offshore oil structures if the lower part of the tower has several legs (tripods, jackets, or similar). However the thrust force on the turbine rotor creates a large static moment at the tower base, and hence the suction piles will experience pull-up forces with a rather large mean component for as long as a strong wind blows from the same direction. The risk is then that over time water is pulled into the bucket, relieving the underpressure. If necessary then active pressure controls (i.e. additional suction) should be used.

Tension leg foundations represent an intermediate stage between fixed and floating solutions and for offshore oil platforms they have up to now only been used in relatively large water depths, at least $150 \mathrm{~m}$, and usually much more. For wind turbines the loading situation is different. The static component of the overturning moment and shear force at the base of a wind turbine tower is namely much larger than for a platform for petroleum production, and a considerable pretension will be required, in order that the tethers (i.e. 'the tension legs') on the downwind side will not go slack. This large pretension adds to the requirement for buoyancy volume in the tower and to tether dimensions. Also the lower ends of the tethers must be kept in place by piling, suction piles or gravity foundations. Tension leg platforms are therefore hardly an alternative, unless the water depth is so large that floating turbines are to be considered, and will be considered in that context herein.

\subsection{Concepts for bottom-fixed offshore turbines}

Bottom-fixed turbines have been built in considerable numbers in shallow water, say in water depth of less than $20 \mathrm{~m}$, and solutions very similar to those used for the landbased turbines have then been employed. It seems that when landbased solutions proved to be feasible in shallow water, they were selected during the short planning periods available for the first offshore parks, even though they might not be optimal under these conditions.

The Beatrice wind farm demonstrator project is in $45 \mathrm{~m}$ water depth, which is claimed to be the deepest wind turbines site yet. It has two REpower $5 \mathrm{MW}$ turbines, each with tubular geometry in the upper part of the tower, and an extension downwards to the sea floor by a specially designed unit, tentatively named 'a substructure'. Time will show whether this split between the tower itself (as designed for onshore sites) and a 'substructure' extending from the tower bottom to the seafloor will be maintained, or whether both components will be integrated into a unified offshore tower. For the Beatrice substructure two Tripod designs and an OWEC jacket quatropod (see Figure 1) were considered, and the quatropod was chosen. Its designers in the firm OWEC Tower drew on their background from the offshore petroleum activities on the Norwegian continental shelf. In Seidel and Foss [7] a fairly detailed comparison of the dynamics of the three alternatives is given. Additional information can be found on the internet site www.owectower.no, from which also the mentioned Seidel and Foss paper can be downloaded. One advantage of the quatropod is that its 
slender members lead to less wave loading. Another advantage is that the tower substructure unit is somewhat stiffer, so that for this turbine the dynamic amplification effects were reduced. It is also interesting to see that vibrations at one of the natural frequencies of the blades excited a group of braces in the quatropod at resonance, giving large local motions and stresses. The authors concluded that a detailed integrated dynamic analysis of the full wind turbine was necessary, in order to find such local dynamic problems and remedy them by a slight design change. For the Beatrice wind turbines also a specially designed Emergency Response Intervention Craft (ERIC) has been developed to transfer people to and from the turbine, see www.beatricewind.co.uk. The turbines are built adjacent to an oil production platform, which can be used as a base for maintenance and repair personnel. The owner will run the demonstrator turbines for a test period of five years. Then an evaluation will be made, which may lead to a dismantling of the two turbines, or an expansion to a full commercial park of up to 200 turbines

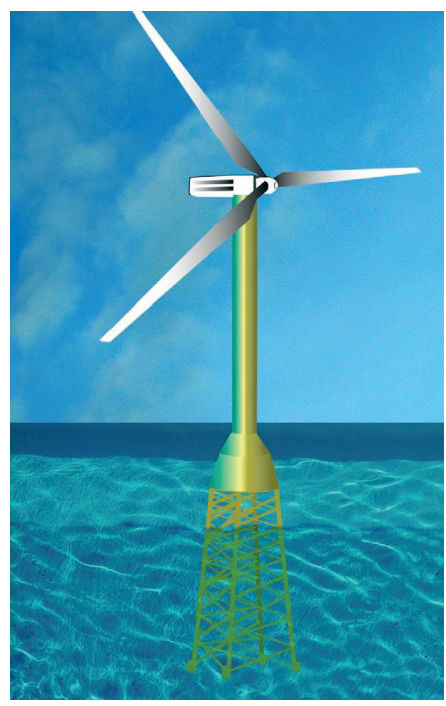

Figure 1: $\quad$ The OWEC tower. (Copyright OWEC tower.)

One interesting concept for a $5 \mathrm{MW}$ offshore wind turbine is presented by the Multibrid development company. Here a hybrid solution is used to achieve the desired alternating current frequency, namely a small, one stage gearbox and a generator with considerably fewer poles than for a direct drive generator. The nacelle weight of 200 tonnes is claimed to be very low for a $5 \mathrm{MW}$ machine. Their use of a glass fibre reinforced plastic sandwich nacelle casing also contributes to the weight reduction. The Multibrid tower consists of a $70 \mathrm{~m}$ tall tubular steel tower, continued smoothly by a nearly $30 \mathrm{~m}$ tall tubular concrete substructure fastened to a base plate, through which 36 concrete piles are driven.

For further information please see http://www.multibrid.com/download /Info_Errection_M5000_191104.pdf 


\subsection{Rough design of a bottom-fixed offshore truss tower}

One idea that to the authors' knowledge has not yet been developed fully is the use of a truss type structure for the entire offshore tower. A student project was therefore run, in which a truss tower was designed to replace the so-called NRELOffshrBsline5 MW tubular tower. Its general characteristics are described in Table 1. Some more information about this tower may be found on http://www.ieawind.org/GWEC_PDF/GWEC\%20Annex23.pdf

Table 1: $\quad$ Gross properties of the NREL $5 \mathrm{MW}$ baseline wind turbine model.

\begin{tabular}{|l|l|}
\hline Rating & $5 \mathrm{MW}$ \\
\hline Wind Regime & $\begin{array}{l}\text { IEC 61400-3 (Offshore) Class 1B / Class 6 } \\
\text { winds }\end{array}$ \\
\hline Rotor Orientation & Upwind \\
\hline Control Variable Speed & Collective Pitch \\
\hline Rotor Diameter / Hub Diameter & $126 \mathrm{~m} / 3 \mathrm{~m}$ \\
\hline Hub Height & $90 \mathrm{~m}$ \\
\hline Maximum Rotor / Generator Speed & $12.1 \mathrm{rpm} / 1173.7 \mathrm{rpm}$ \\
\hline Maximum Tip Speed & $80 \mathrm{~m} / \mathrm{s}$ \\
\hline Overhang / Shaft Tilt / Precone & $5 \mathrm{~m} / 5^{\circ} /-2.5^{\circ}$ \\
\hline Rotor Mass & $110,000 \mathrm{~kg}$ \\
\hline Nacelle Mass & $240,000 \mathrm{~kg}$ \\
\hline Tower Mass & $347,460 \mathrm{~kg}$ \\
\hline Reference Site & $\begin{array}{l}\text { National Data Buoy Center (NDBC) Buoy } \\
44008\end{array}$ \\
\hline
\end{tabular}

The distributed tower properties of this tubular model (NRELOffshrBsline5 MW) are based on a base diameter of $6 \mathrm{~m}$ and wall thickness $0.027 \mathrm{~m}$, a top diameter of $3.87 \mathrm{~m}$ and thickness $0.019 \mathrm{~m}$, and effective mechanical steel properties of the tower used in the DOWEC (Dutch Offshore Wind Energy Converter) study. The Young's modulus, shear modulus, and effective density of the steel are taken to be, respectively, $210 * 10^{9} \mathrm{~Pa}, 80.8 * 10^{9}$ $\mathrm{Pa}$, and $8500 \mathrm{~kg} / \mathrm{m}^{3}$. The increase above the typical value of $7850 \mathrm{~kg} / \mathrm{m}^{3}$ for the density of steel is in order to account for paint, bolts, welds, and flanges that are not covered through the tower thickness data. The radius and thickness of the tower are assumed to be linearly tapered from base to top. The thickness of the tower was scaled up relative to the values indicated above in order to strengthen it, since the REpower 5M machine has a larger tower-top mass than the DOWEC $6 \mathrm{MW}$ machine. An increase of $30 \%$ was chosen to ensure that the first fore-aft (FA) and side-to-side (SS) tower frequencies lie well between the $1 \mathrm{P}$ and $3 \mathrm{P}$ frequencies through the operational range of the wind turbine. ( $3 \mathrm{P}$ is the frequency at which a blade will pass the tower, $\mathrm{P}$ is the rotor frequency.) 
The resulting overall (integrated) tower mass is $347500 \mathrm{~kg}$ and its center of gravity is on the tower centerline at $38.234 \mathrm{~m}$ above the still water level. This result follows directly from the overall tower height of $87.6 \mathrm{~m}$.

The calculation model for the turbine tower is a cantilever beam clamped at the sea floor, see Figure 2. The most important loading for turbine towers is the wind loads, and notably the rotor thrust loading. A maximum value of roughly $700 \mathrm{kN}$ is found in the figure of thrust loads versus wind speed in the above mentioned NREL report on NRELOffshrBsline5 MW. Considering the possibility of horizontal loadings from other factors the thrust load has been increased to $800 \mathrm{kN}$ in the present analysis.

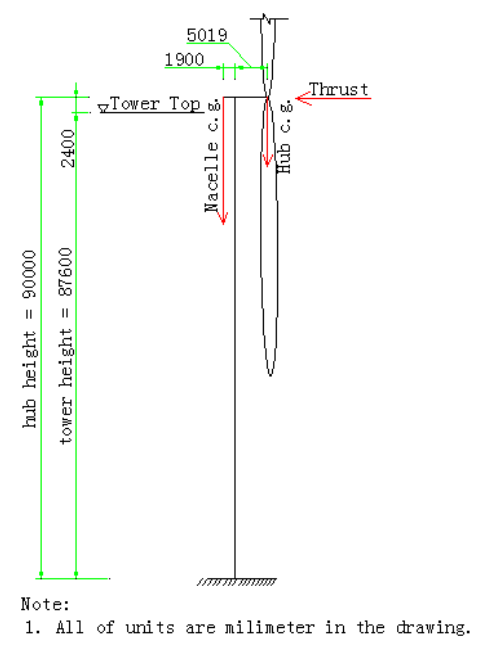

Figure 2: Calculation model of the truss tower.

The weights of the nacelle and hub balance each other, so that they give rise to no moment at the top of the tower. The moment at the top of the tower from the thrust loading is equal to $800 \times 2.4=1920 \mathrm{kN}-\mathrm{m}$.

In Figure 3 is shown the truss tower designed as an alternative to the previously described tubular tower. The sizes of components and cross sections were chosen so that the lowest natural frequencies of the truss tower should be roughly equal to those of the existing tubular tower. Its weight is 155 tonnes, or less than $50 \%$ of that of the tubular tower. The natural frequencies of the truss tower were found by ANSYS. The first fore-aft (FA) and side-to-side (SS) tower frequencies of $0.33 \mathrm{~Hz}$ were exactly equal to those of the tubular tower $(0.33 \mathrm{~Hz})$. The third frequency of the truss tower was a torsional mode at $1.56 \mathrm{~Hz}$, which is considerably lower than that of the tubular tower $(2.94 \mathrm{~Hz})$. This means that third mode resonance may be more of a problem for the truss tower. By increasing the dimensions of the diagonals or augmenting their numbers a higher torsional stiffness could be obtained, but then of course the costs would increase, too. For the time being it is hypothesized that this tower could be shown to have sufficiently long fatigue life. If torsional vibrations turn out to be a problem they could be neutralised by advanced pitch control of the rotor blades. 


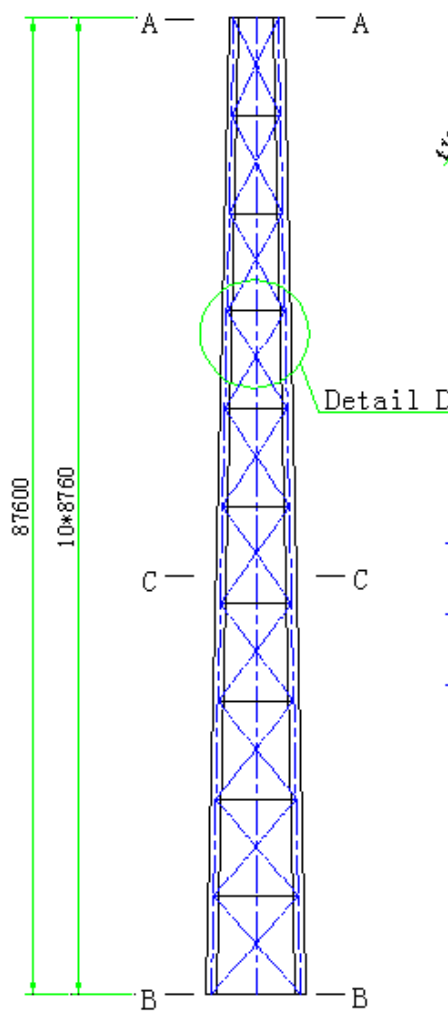

Figure 3: Layout of the truss tower.

A static analysis of the truss tower was also performed, showing stress levels of up to $105 \mathrm{MPa}$ both in the legs and in the diagonals. This value appears to be satisfactory, even when considering that dynamic stresses must be added to this.

The truss tower was also checked for buckling, and a load factor of 20.5 was found, which is far to the safe side.

In conclusion weight savings of about $50 \%$ relative to the tubular tower were reached, which means that truss towers appear to be an economical option for lager wind turbines. Further savings might be possible in view of the low stresses in the components and the possibility of widening of the tower base. But no firm conclusions can be drawn before a careful dynamic analysis has been carried out, in which loading from turbulent wind and blade excitation has been included.

\subsection{Some comments concerning floating offshore turbines}

There are as of now no floating offshore wind turbines that are ready for mass production, but prototype testing may be getting close.

The purpose of the structure for a Horizontal Axis Wind Turbine (HAWT) is to support the rotor in a position well above the ground, and to resist the loading that is generated during operation. Therefore turbine structures tend to be 
relatively slender towers. Also, since the wind can come from any direction, these towers must have no significant protrusions on either side, and guy cables are usually avoided. The rotor is on the upwind side on most existing HAWTs, to minimize the influence of the tower on the wind field at the rotor. Then the rotor blades must be made stiff, to avoid collisions with the tower. To help in this respect, the rotor is often mounted on an inclined axis so that the lower part of the rotor slopes away from the tower, and often also the blades are given a curvature away from the tower. A drawback of this is that the centrifugal forces then introduce a bending moment at the root of the blade that adds to the moment from the thrust force. For floaters the problem of keeping the rotor facing the wind becomes somewhat more difficult, since the mooring lines usually will provide insufficient stiffness for rotations about a vertical axis. Therefore for floaters often downwind rotors are considered, since they are stable under shifting wind, and it is argued that a much smaller yawing mechanism is needed. However Hywind (see later) uses an upwind rotor and mooring by three lines that split in two parts near the turbine, so called 'crow legs'.

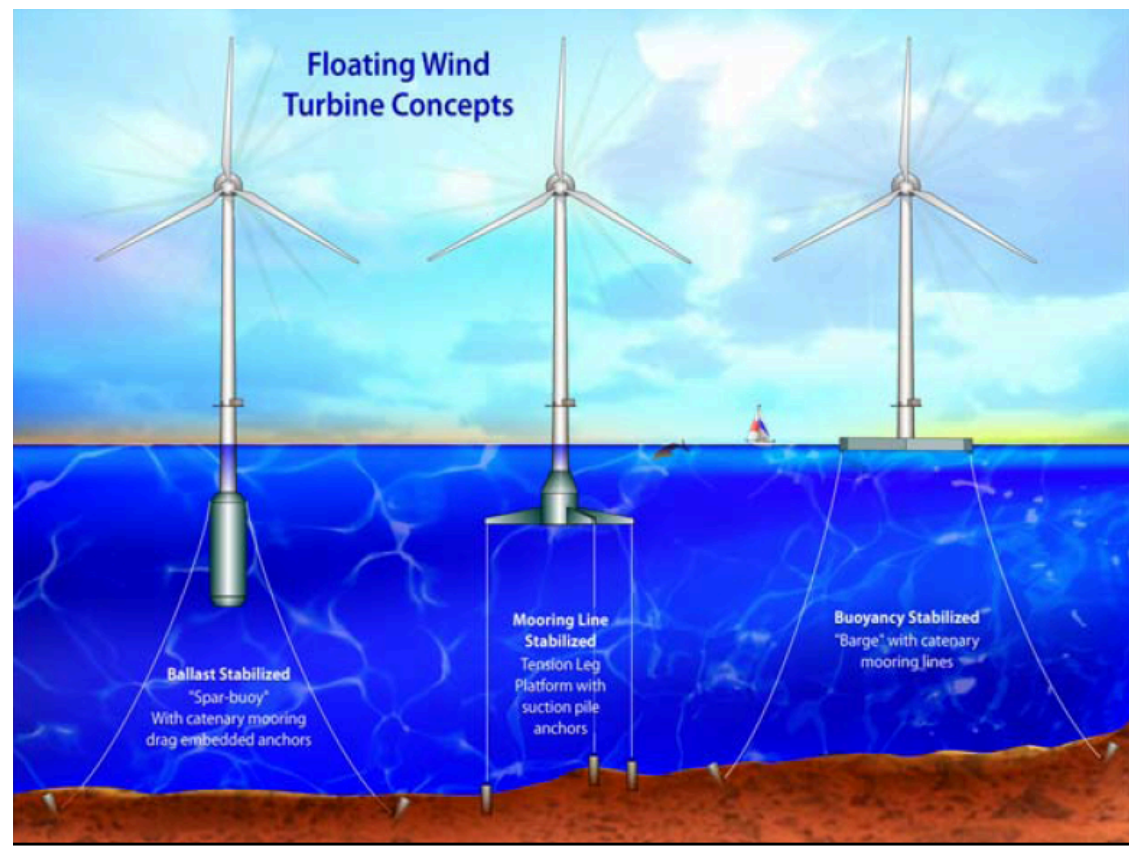

Figure 4: Types of floating wind turbines. From Jonkman and Sclavounos [3].

A major consideration for a floating wind turbine is hydrostatic stability. This is especially true if the tower is a slender tube, because then the metacenter will be at the position of the buoyancy center, since the effect of the waterplane area will be negligible. To get the center of gravity below the center of buoyancy imposes severe restraint on the design, considering that the nacelle, hub and rotor 
are positioned at least $150 \mathrm{~m}$ above the center of buoyancy and in present designs typically weigh at least 350 tonnes for a $5 \mathrm{MW}$ unit. Reduced top weight would accordingly be extremely valuable for this type of floaters. One promising concept for reduction of top weight by roughly $50 \%$ is presented by the small Norwegian firm ChapDrive AS, which uses hydraulic power transmission. Then the shaft in the nacelle drives a pump, which via a hydraulic line drives a hydraulic motor at the bottom of the tower. Small scale experiments indicate that the efficiency for this system is as high as for a mechanical gear box. Patents are pending and large scale testing is in progress. Also the non-metallic direct drive generators mentioned before, may be an alternative.

Jonkman and Sclavounos [3] and Wayman et al [10] present 3 types of floating offshore turbines, see Figure 4. Professor Sclavounos recommends the second alternative in this figure, the tension leg platform with suction piles, as the preferable alternative. The company Hydro has studied a version of the first alternative, the ballast stabilized turbine, see http://www.hydro.com/ en/press_room/news/archive/2005_11/hywind_en.html.

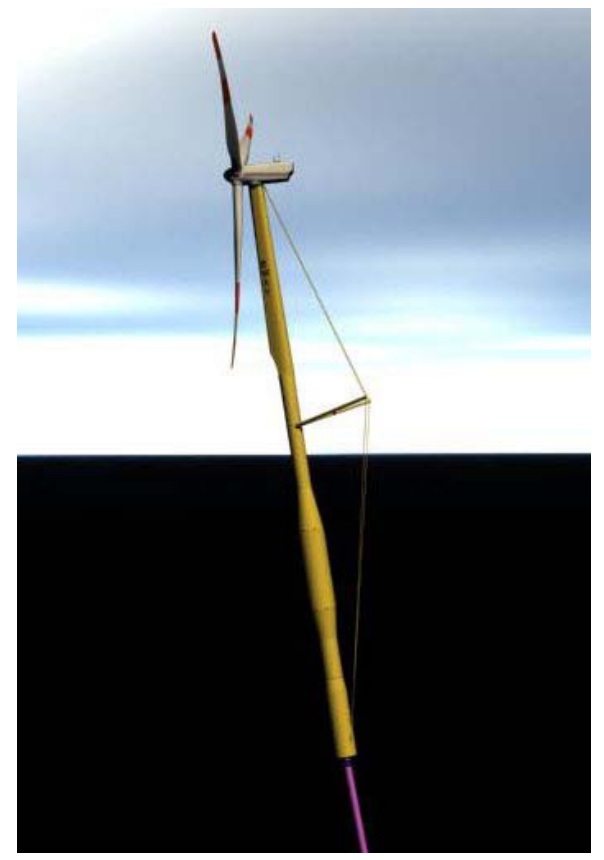

Figure 5: The Sway floating wind turbine. (Copyright Sway AS.)

They have conducted tests in the Marintek ocean basin in Trondheim, and are planning to start a demonstration project in 2007. The lower part of their structure is planned to be a $120 \mathrm{~m}$ tall cylinder in concrete. The wind turbine is planned to be completed near land and towed to the site where it will be moored by three sturdy cables. During production active pitch control will be used to minimize motions, and in the process also to harvest energy from the waves. 
Transportation of a complete unit in vertical position requires considerable water depth, say $100 \mathrm{~m}$ or more, everywhere on the route from the construction site to the place of operation. This is not a problem in Norway, but may be prohibitive on many of the sandy coasts that are seen around the world. The Sclavounos tension leg platform will have much lower draft, and is planned to be kept stable during tow by suitable ballasting procedures.

A third floater alternative is presented by Sway, see Figure 5. Here the upper part of the tower is streamlined to minimize the disturbance of the wind acting on the downwind rotor. Further the slender tower is stiffened by the taut cable arrangement on the upwind side of the tower. Sway plans to start construction of a one quarter size prototype in 2007, and tentatively plans to build the first full scale prototype in 2008-2009.

\section{Conclusions}

- A selective and incomplete review of the status of the development of offshore wind turbines has been given.

- A fair number of offshore bottom-fixed turbines have been built, all but one in water depths less than about $20 \mathrm{~m}$. The concepts chosen have with few exceptions been adapted with small changes from landbased solutions, and the costs for the produced energy have been roughly twice the costs from landbased turbines.

- A multitude of novel concepts for bottom-fixed wind turbines have been suggested by the engineering community, but so far few of them have been realized, so their impact on the final costs are not yet known. However in any case more efficient production of existing components will cause the costs to drop.

- Floating offshore wind turbines are yet in the conceptual stage. However if energy production at sufficiently low prices can be achieved by floaters, then considering the enormous areas available, this may become an essential contribution to the energy supply of future generations.

\section{References}

[1] B W Byrne, G T Houlsby, "Assessing novel foundation options for offshore wind turbines", World Maritime Technology Conference, London March 2006, http://www-civil.eng.ox.ac.uk/people/bwb/papers/ MAREC011_paper.pdf

[2] EWEA: "The facts", CD distributed at the EWEC 2004 conference, London 2004

[3] J M Jonkman, P D Sclavounos, "Development of fully coupled aeroelastic and hydrodynamic models of offshore wind turbines", Presented at the 2006 ASME Wind Energy Symposium, Reno, Nevada, January 10-12, 2006, also available at http://www.nrel.gov/docs/fy06osti/39066.pdf 
[4] G Moe, "What is the optimum size of a wind turbine?", proceedings OMAE 2007, (to appear)

[5] P Schaumann, P Kleineidam, F Wilke, "Fatigue Design bei OffshoreWindenergieanlagen", Stahlbau 73 (2004a), S. 716-726, 09/2004

[6] P Schaumann, P Kleineidam, F Marten, "Fatigue design of support structures of Offshore Wind Energy Converters", Nordic steel conference (2004b), Copenhagen, 06/2004

[7] M Seidel, G Foss, "Impact of different substructures on turbine loading and dynamic behaviour for the DOWNVInD Project in $45 \mathrm{~m}$ water depth", Proceedings of EWEC, Athens 2006

[8] T Soerensen, P Nielsen, M L Thoegersen, "Recalibrating wind turbine wake model parameters - Validating the wake model performance for large offshore wind farms", proceedings of EWEC, Athens 2006

[9] van der Tempel, J., Slootweg, J.G., Bierens, R.W.P., Blaazer, A.J., "Interconnectors, the power of cables", World Energy Conference and Exhibition, Berlin, July 2002

[10] E N Wayman, P D Sclavounos, S. Butterfield, J Jonkman, W Museal, "Coupled dynamic modeling of floating wind turbine systems", Paper no. OTC 18287, Offshore Technology Conference 2006 